\title{
A SALA DE AULA INVERTIDA NA DISCIPLINA LITERATURA NO ENSINO A DISTÂNCIA
}

\author{
BARUERI/SP MARÇO/2018 \\ Roseli Gimenes - UNIP - roseligi@icloud.com \\ Tipo: Investigação Científica (IC) \\ Natureza: Relatório Final de Pesquisa \\ Categoria: Métodos e Tecnologias \\ Setor Educacional: EDUCAÇÃO SUPERIOR
}

\begin{abstract}
RESUMO
A proposta deste artigo é apresentar uma discussão sobre sala de aula invertida para a disciplina literatura no ensino a distância superior de Letras Licenciatura ou Bacharelado.O objetivo deste trabalho é apontar metodologia ativa para o ensino de literatura que mova discentes em aula, saindo do discurso passivo teórico.O professor não é mais transmissor de conteúdo e detentor do conhecimento. $O$ aluno deixa de ser receptor e tem um papel ativo,buscar o conhecimento,ser protagonista. Os procedimentos metodológicos para que funcione implicam em como se dá a SAl,quais são os principais argumentos que defendem essa metodologia e de explanações de como trabalhar essa disciplina.Ler textos antes da aula, assistir a filmes homônimos de obras literárias canônicas ou não. A fundamentação teórica desta proposta encontra-se em autores que entendem a SAl como relação ensino-aprendizagem dialógica e mediada pelas Tecnologias Digitais da Informação e Comunicação - TDIC, Eric Mazur, Jonathan Bergman, José Armando Valente. Os principais resultados a que se pode chegar com a SAl são a leitura reflexiva e dialógica da obra estudada, a relação interdisciplinar dela com outras artes.
\end{abstract}

Palavras-chave: sala de aula invertida, literatura, ensino.

\section{AGRADECIMENTOS}

\section{À EQUIPE DA UNIP INTERATIVA}




\section{Introdução}

Quando se fala de aulas da disciplina literatura, nacional ou não, parece óbvio pensar imediatamente em SAI - sala de aula invertida - porque, no mínimo, é necessária uma leitura prévia, fora da sala de aula presencial, do texto a ser estudado. Torna-se mesmo impossível que essa aula aconteça sem que os estudantes tenham lido a obra.No entanto, neste artigo, justamente falaremos em SAI tendo em vista os conceitos que envolvem as TDIC. Nesse sentido, trata-se do aproveitamento dessas tecnologias que ajudam o estudante a preparar-se antes da aula para melhor empenho dentro da aula.Objetivo:A proposta deste artigo é apresentar uma discussão sobre sala de aula invertida para a disciplina literatura no ensino presencial superior de Letras Licenciatura ou Bacharelado.O objetivo deste trabalho é apontar metodologia ativa para o ensino de literatura que mova discentes em aula, saindo do discurso passivo teórico.O professor não é mais transmissor de conteúdo e detentor do conhecimento.O aluno deixa de ser receptor e tem um papel ativo,buscar o conhecimento,ser protagonista.Os procedimentos metodológicos para que funcione implicam em como se dá a SAI,quais são os principais argumentos que defendem essa metodologia e de explanações de como trabalhar essa disciplina.Ler textos antes da chegada do estudante à aula, assistir a filmes homônimos de obras literárias canônicas ou não. $O$ referencial teórico desta proposta encontra-se em autores que entendem a SAI como relação ensinoaprendizagem dialógica e mediada pelas Tecnologias Digitais da Informação e Comunicação - TDIC,Eric Mazur, Jonathan Bergman,José Armando Valente.O principais resultados a que se pode chegar com a SAI são a leitura reflexiva e dialógica da obra estudada, a relação interdisciplinar dela com outras artes.O trabalho apontará a explanação teórica do que é a SAI - com suas principais atividades demandas por especialistas e suas implicações - para, em seguida, mostrar exemplos de como a SAI pode ser aplicada nas aulas de literatura. E, finalmente, verificar os resultados positivos e ativos do uso dessa metodologia.

\section{SAI, o que é?}

De maneira sintética e simples, podemos dizer que a sala de aula invertida ou flipped classroom é uma metodologia ativa que ressignifica o papel do aluno, do professor e da aprendizagem. Coloca o aluno no centro do processo ensino aprendizagem, como protagonista e promove o desenvolvimento de uma aprendizagem ativa, investigativa e colaborativa.

SAI, conforme a obra de BERGMANN e AARON (2012), é uma metodologia bastante didática e acessível de ser colocada em uso. No formato de aula invertida, o professor 
grava vídeos de curta duração em que apresenta os conceitos fundamentais de um determinado conteúdo. Um ponto importante é que, dedicando o tempo em aula para a aplicação dos conceitos, faz com que os professores tenham mais facilidade em identificar as dificuldades e aquilo que não foi bem compreendido.Imagine uma aula movida pelos problemas ou interesses identificados pelos alunos. Os estudantes exploram um problema da vida real e desenvolvem soluções até que, de repente, percebem que precisam saber como executar determinada função matemática para aplicar o que conceberam.(BERGMANN;AARON, 2012,p 45)Dadas as proporções de uma aula sobre literatura, os alunos poderiam, assistindo a um vídeo ou até, como apontaremos, jogando um game, entender questões do uso de linguagem figurada na literatura.A idéia do uso da SAI é também a combinação de metodologias diferentes.

A respeito disso, considerando a multiplicidade de metodologias ativas, o professor pode usar também a Instrução pelos Colegas $(\mathrm{IpC})$ que é um método desenvolvido desde 1991 por Eric Mazur(ARAUJO; MAZUR, 2013). Os encontros podem ou não ser precedidos por material introdutório extra-classe. Nesse caso, os alunos respondem três questões de texto livre, que contam pontos na avaliação. Duas questões são relacionadas a aspectos-chave do tema e na terceira questão o aluno descreve as dificuldades ou motivações que encontrou na leitura. Com isso, ao mesmo tempo em que a leitura é incentivada, o professor recebe uma visão prévia sobre as dificuldades dos alunos com o conteúdo.

De maneira geral, a sala de aula invertida muda a estratégia metodológica:

No ensino tradicional a aula serve para o professor transmitir informação para o aluno que, após a aula, deve estudar e ser avaliado. Nessa nova abordagem, o aluno estuda antes da aula e ela se torna um lugar de aprendizagem ativa,em que há perguntas, discussões e atividades práticas. O professor trabalha as dificuldades dos alunos, ao invés de apresentações sobre o conteúdo da disciplina.(VALENTE,2017)

Sabem os educadores que propostas como a SAI não são novas no sentido de requerer à educação modelos diversos e metodologias ativas. Já as pensaram teóricos como os estudos de Vygotsky (1998) sobre aprendizado que decorrem da compreensão do homem como um ser que se forma em contato com a sociedade. Na ausência do outro, o homem não se constrói homem, escreveu o psicólogo. Já clara a idéia de que o educando assimilaria o objeto de estudo fazendo uso de uma prática dialética com a realidade, em contraposição à educação bancária, tecnicista e alienante, de acordo com Paulo Freire(2009).O educando criaria sua própria educação, fazendo ele próprio o caminho, e não seguindo um já previamente construído; libertando-se de chavões 
alienantes, o educando seguiria e criaria o rumo do seu aprendizado.

Apresentação e discussão de resultados:SAI na disciplina literatura: a aula de literatura no ensino superior, no caso de curso de Letras, costuma ser considerada atrativa e interessante porque faz parte da escolha de estudantes que serão professores ou tradutores. Esse interesse pode esmorecer se os educandos se deparam apenas com aulas tradicionais centrada na figura do professor. A aula de literatura só funcionará se um básico ponto figurar: a leitura anterior do texto escolhido, prosa ou poema.O primeiro ponto básico da SAI é a preparação do estudante antes de ele estar na aula. Um deles, então, necessário, é a leitura da obra. Quase sempre, se no caso de poemas, a leitura é feita nesse momento. É possível ler um poeta como Camões (1524?-1580)sem nada saber do que foi o movimento literário do classicismo em Portugal? Um estudante do século XXI ainda que continue a ter dificuldades de leitura, é o que melhor compreende a SAI. Por quê? Porque, evidentemente, vive em meio a ferramentas digitais, por exemplo e principalmente, em EAD. Os estudantes atualmente já estão ligados às questões tecnológicas, mas agora chegou a vez de os professores pensarem seriamente em novos métodos de ensino. (GIMENES,2017)

Eis a sala de aula invertida.Como usar na disciplina literatura?Partindo do princípio de SAI já explicado, o professor, que também precisa ser 'alfabetizado' em novas tecnologias ativas, pode propor em seu ensino de literatura, além da óbvia leitura do texto:

Jogos, games, RPG: Jogos, como o game, caracterizam-se por linguagem híbrida porque há a linguagem visual em movimento, há a narrativa verbal, há a sonoridade de músicas ou mesmo da fala oral. Nesse sentido, a linguagem híbrida dos jogos está bem próxima da do cinema.O preconceito que existe em relação a jogos desaparece quando pensamos que não há linguagem pura, portanto a literatura, uma narrativa, não é única e preciosa e muito menos pode prevalecer sobre outras linguagens, já que a própria narrativa dispõe-se em várias linguagens. Mais ainda quando nos lembramos de que a narrativa teve por muitos séculos uma característica oral, sonora, e só muito recentemente, com o advento da prensa, é que essa narrativa tornou-se verbal/escrita. Significa dizer que a transmissão oral de histórias tem uma longa trajetória. Ainda em algumas civilizações ela é um dos grandes meios de comunicação e de transmissão de conhecimento entre seus membros. O fato de vivermos, e isso está mudando, em meio a papéis, não quer dizer que haja hegemonia da escrita.Verdade que se tem dado aos games o estabelecimento de nova relação entre as artes visuais, a cultura da comunicação e a indústria do entretenimento. (SANTAELLA, 2007,279). Significa que os games tratam particularmente da simulação que deixa jogadores muito próximos da 
sensação do real. Muito já se falou sobre a questão de simulacro da arte, qual seja, verossimilhança com o real. Ao que parece, nos games, esse simulacro, no caso visual, é fantástico. A literatura vista como ficção também faz simulacros. Ninguém há de afirmar cem por cento que uma narrativa é de fato um fato real. Mesmo as narrativas épicas, como Os Lusíadas, fazem simulacro do real. Gigantes, monstros, levam nomes dos chamados seres reais da sociedade retratada.O ser humano, como outros animais, gosta de brincar. E no simulacro com a brincadeira inventa a arte, os jogos. Assim nos ensina Lucia Santaella:

Um elemento motriz e comum a todas essas criações, que brotam dos arcanos do psiquismo humano, está no lúdico, na capacidade para brincar, no dispêndio, sem finalidade utilitária, da energia física e psíquica acumulada. (...) Não é por ocaso que o humano, único animal que chora e ri, foi capaz de transmutar a brincadeira em jogo, em arte, em música, em poesia, todos eles brincadeiras codificadas e, por isso mesmo, complexas, emblemas da dignidade humana e do orgulho que a espécie pode ter de si mesma. (SANTAELLA, 2007,405,406)

Acerca de jogos: literatura e RPG , anos atrás, um aluno de Letras apresentou como tema de seu Trabalho de Curso a relação profícua entre literatura e RPG. O que é RPG? Nas palavras do autor:

O RPG - role playing game, ou jogo de interpretação - surgiu na década de 70 nos Estados Unidos, criado inicialmente sob o nome de Chainmail, um complemento para os antigos jogos de miniaturas de estratégias de batalhas, como o WAR, complemento que possuía o caráter de obter o máximo de interpretação ao invés de apenas reproduzir o jogo de estratégia. (...)Assim sendo, é possível constatarmos as grandes duas bases do RPG: as regras e a criatividade. Todo jogo de RPG é um jogo de interpretação baseado em um cenário - local onde, no imaginário dos jogadores, o jogo acontece - que possui um conjunto particular de regras que permite a aplicação de elementos típicos da realidade, como é o acaso. Além disso, o conjunto de regras em si permite por parte dos integrantes do jogo uma maior verossimilhança nos acontecimentos narrados e consequentemente evita problemas a respeito de passagens duvidosas da narração. Todo jogo de RPG tem um mínimo de elementos que devem ser seguidos tanto pelo narrador/mestre - pessoa que elabora a história, narra e interpreta os desafios - e os jogadores - pessoas que criam as personagens que viverão nessa história e serão os protagonistas dela - a fim de se ter um jogo divertido e coerente. (MINETTI,2009,sp)

Pela explicação acima, logo se vê toda relação entre o jogo e a literatura. Termos como narrativa, verossimilhança, personagens, mostram como jogar está relacionado à ficção 
literária. Interessante que se trata de um "jogo de interpretação". Nesse sentido, leva a crer que se trata de trabalho interativo entre jogo e jogador. Ou texto e leitor. Ledo engano quem pensa que a literatura, digamos, um livro, não seja interativo. Todos são. Caso ímpar é o romance Memórias Póstumas de Brás Cubas em que o narrador joga o tempo todo com o leitor fazendo -o ir e vir pela narrativa, desafiando-o a resolver enigmas, relembrando-o de passagens importantes da história. Como qualquer jogo, ir e vir é parte da diversão. Avançar uma casa, perder uma jogada. Ganhar outra. Machado de Assis sabia dessa relação como astuto escritor de seu tempo, afinal como nos diz Huizinga (Apud SANTAELLA, 2007, 406), " o lúdico é mais antigo que a cultura”.

A proposta do aluno consistiu em trabalhar uma obra literária clássica do classicismo português, um épico, Os Lusíadas, em RPG. Por quê? Como futuro professor, o aluno já sabia que textos clássicos são dores de cabeça para jovens em idade escolar média. Quem, de fato e verdade, leu essa obra inteira? Quantos apenas dedilham alguns versos, aqueles mais famosos? Ou associam gigantes, como Adamastor, a uma montanha geograficamente real? Uma narrativa em versos, difícil mesmo. Se transformada em jogo, lúdico e prazeroso, estudantes poderiam se interessar pela narrativa. E eis o pulo, do RPG para a Literatura.

A educação se beneficia dos jogos na aprendizagem. Longe de banalizar a obra, o autor a torna instigante a jovens acostumados às brincadeiras de jogos, como o RPG. Necessário que se perceba que não é qualquer pessoa que pode sair transformando obras literárias em filmes, jogos, teatro. Importante que sejam conhecedores do código ao qual se transfere a obra, da linguagem, como já apontamos, de cada ligação. Conhecimento, no caso desse RPG, de quem foi Camões, qual sua época literária, qual a cultura da sociedade da época, que obra é Os Lusíadas, por que ela foi escrita, qual a importância de sua linguagem poética? Na mesma medida, torna-se fundamental conhecer a linguagem, no caso, de RPG. Assim como um cineasta faz filmes cuja transcriação é literária, um jogador de RPG pode apenas jogar. Ou criar um RPG transcriando uma obra literária, como fez o autor.

A que conclusões, depois de testado o jogo algumas vezes, chegou o autor?

Assim, com o encerramento deste Trabalho de Curso se chega à conclusão de que este hobby tão difundido em outras partes do mundo possui verdadeiramente o potencial de ferramenta educacional que tantos pesquisadores e pensadores já apontaram como necessária para a criação de pessoas mais autônomas, críticas e leitoras. Dessa forma, aquilo que sempre foi uma forma de diversão se torna o ápice da vida acadêmica e o auge das pesquisas que foram realizadas nestes três anos de estudo(...)( MINETTI, 
$2009, \mathrm{sp})$

Significa que a pesquisa deu certo, que alunos passaram a se interessar pela literatura de maneira mais prazerosa porque puderam brincar com ela.

Sobre jogos: literatura e game, continuamos com Santaella que nos diz que(2007) a indústria de games fatura mais do que a automobilística ou a bélica. Fácil entender que as pessoas estão levando a sério o jogar/brincar. Nesse sentido, em que pese essa séria importância, os games superaram o preconceito? Assim como na citada relação de literatura e RPG, professores pensam mesmo em acreditar que estão lidando com arte quando associam literatura e games? Longe disso, poucos professores acreditam que games são boa transcriação poética de obras literárias. Continuam crendo que são jogos e são apenas prazerosos. Significa não dar crédito ao que Barthes nos fala sobre O prazer do texto. Então, a literatura precisa ser tediosa por que não pode dar prazer?.( SANTAELLA, 2007, 407)

O caráter híbrido dos games envolve programação, roteiro de navegação, design de interface, técnicas de animação, usabilidade.( SANTAELLA, 2007, 408). Segundo Neitzel (Apud SANTAELLA, 2007, 409), a diversidade dos games divide-se em três classes: jogos de ação, jogos de inteligência e jogos de exploração. Em todos eles, uma condição se mostra em particular, a participação. Sem ela, não há jogo. E, claro, a interatividade que faz com que o jogador seja um coautor:

Um exemplo que há na Literatura Brasileira foi a criação de games com base em três obras, uma do período do romantismo; outra, do período do naturalismo e mais uma do realismo. Transcrevemos abaixo as informações retiradas do site que fazem menção ao projeto criado por Celso Santiago e que poderão levar o leitor à busca por esses games:

Com a proposta de mostrar aos jovens internautas que a literatura clássica pode ser divertida e interessante, o gestor cultural Celso Santiago desenvolveu o projeto Livro e Game, que adaptou para o universo dos jogos virtuais os clássicos brasileiros "O Cortiço" (Aluísio Azevedo), "Memórias de um Sargento de Milícias" (Manuel Antônio de Almeida) e "Dom Casmurro" (Machado de Assis).Três clássicos nacionais que viraram jogos virtuais:O Cortiço,Memórias de um sargento de Milícias e Dom Casmurro(www.fael.edu.br/.../classicos-da-literatura-brasileira-viram-jogos-virtuais/ acesso em 19/11/2014)

Recentemente, foi criado o The Pickle Index( novembro de 2015), que poderia ser um livro comum, mas se trata de um livro-aplicativo, criado pelo britânico Russell Quinn e 
pelo americano Eli Horowitz. Esse aplicativo mistura leitura e game.(BOLDRINI,2015)

$\mathrm{Na}$ esteira de criação de jogos educativos, corre o aumento e instituições que procuram ensinar robótica e jogos tentando a popularização que tem as escolas de língua inglesa. Caso da Future Code, escola de computação que oferece aulas de robótica, desenvolvimento de aplicativos, jogos 2D e Minecraft. Ainda é difícil convencer muitos pais para levarem seus filhos a essas escolas já que sabem que as crianças conhecem bem as ferramentas digitais. No entanto, ter essa facilidade não é apenas o único fator da natividade digital.(SOARES,2016).

Redes Sociais,Blogues e Sites literários:Entre os que estão nas redes, há também escritores como é o caso de Pedro Gabriel que tem 1,6 milhão de seguidores. Ele é autor do projeto "Eu me chamo Antônio". Um outro escritor, Zack Magiezi, discursa nas redes em forma de poesia. Ele indica o estilo digital apontando que o texto tem que ser sucinto, como um soco. Interessante é que Zack mescla seus textos datilografando-os, depois fotografa com o celular e posta na rede. Mais um autor editado e que deverá aumentar o número de seguidores e de leitores.Lembramos aqui o caso da escritora Clarah Averbuck que fez processo semelhante ao de Pedro Gabriel. Seus textos conquistaram leitores por meio de seu blogue.O fato é que a literatura nas redes, de certa forma, democratiza o acesso de leitores. No caso do twitter, por exemplo, seus 140 caracteres mudam a maneira tanto de escrever como de ler

No Wattpad, aquilo que sempre se chamou de escrita solitária passa a uma prática social (de rede) informal e íntima com resultados compostos e que são consumidos imediatamente. Não há distância entre autores e leitores. A literatura prolifera também em blogues criados por autores formando um espaço de interação criativa, como já mostramos no caso de Clarah Averbuck, e mesmo nos lugares em que a poesia de Spalding(2016) é mostrada aos leitores. Significa também que blogues abrigam literatura e crítica literária e neles há espaço para contribuições.

Alguns exemplos citados, há muito mais circulando nas redes.

\section{Considerações Finais}

Por aquilo que apontamos acima, o professor pode aproveitar esse material para que estudantes previamente possam ler as obras literárias, mas também já desenvolvam um hábito crítico de ler a literatura, ou seja, enquanto joga um game baseado, por exemplo, na obra O cortiço, de Aluísio de Azevedo, ele vivenciará algo diferente da leitura. Aproveitará de seu universo de estudante imerso na ubiquidade, aquele que está imerso 
em vários mundos, para ampliar sua visão literária. Nesse sentido, o game facilitará sua ida à obra impressa, no mínimo, por curiosidade e para poder jogar melhor.

Na mesma medida, o jogador de RPG verá facilitada sua leitura de Os Lusíadas, de Camões. Também, no mínimo, para jogar melhor já que na leitura encontrará muitas respostas narrativas sobre o melhor meio de aproveitar o jogo.

Os exemplos que apontamos vão de obras canônicas como Os Lusíadas a outras bem pouco conhecidas como romances de Clarah Averbuck que são potencializados nos blogues e nos jogos, além de acesso à fortuna crítica literária disponível nos sites citados.

O que tudo isso significa? Que o professor recomenda essas visualizações de blogues, de sites. Recomenda o jogo, o game, o navegar pelo ciberespaço que dará ao estudante a dinâmica de melhorar sua performance em sala de aula. Necessariamente como prediz a SAI o professor de literatura tem em sites e blogues conteúdos e críticas sobre a literatura. Material que o aluno pode ver e rever antes da aula.No momento em que 0 professor iniciar a discussão sobre qualquer uma dessas obras aqui citadas - e outras terá na aula um estudante que já passou pelas TDIC ( vídeos, jogos, sites) em função de uma aula de literatura. Em outras palavras, um aluno motivado e ávido por discutir determinada obra em aula.

Eis a palavra chave: motivação. Motivação para chegar à aula munido de muita criatividade e vontade para discutir, argumentar, participar da aula de literatura.

\section{Referências}

ARAGUAIA, Jurandir. O twitter é uma nova literatura?São Paulo:agBooks,2012.

ARAUJO, I. S.; MAZUR, E. Instrução pelos Colegas e Ensino sob Medida: Uma proposta para engajamento dos alunos no processo de ensino-aprendizagem de Física. Caderno Brasileiro de Ensino de Física, Florianópolis, v. 30, n. 2, p. 362- 284, 2013.

BERGMANN, Jonathan. SAMS,Aaron. Flip your classroom. Washington:Iste PubishingASCD.2012.

BOLDRINI,Angela. Livro-aplicativo mistura leitura e game.Jornal Folha de São Paulo(Caderno llustrada),28 nov2015,pC3. 
CAMPOS, Vinicius.O amor nos tempos de blog.São Paulo:Companhia das Letras,2010

FREIRE,Paulo.Pedagogia da autonomia: saberes necessários à prática educativa. Rio de Janeiro:Paz e Terra. 2009.

GIMENES, Roseli. Literatura brasileira: do átomo ao bit.São Paulo:Scortecci.2017.

MINETTI,Santiago.RPG\&Camões: uma visão lúdico-prática sobre aprender e ensinar Os Lusíadas.Monografia de Licenciatura em Letras,Universidade Paulista,Campus Alphaville,São Paulo,2009.

SANTAELLA, Lucia. Da poesia concreta à ciberpoesia. In: SANTAELLA, Lucia. Linguagens líquidas na era da mobilidade. São Paulo: Paullus, 2007.

SANTAELLA, Lucia. Comunicação Ubíqua. Repercussões na cultura e na educação. São Paulo: Paulus. 2013.

SOARES, Jussara.Escolas de programação querem ser populares como curso de inglês.Folha de São Paulo.Caderno MPME, 17 de abril de 2016. p4

VALENTE, José Armando. Aprendizagem ativa no Ensino Superior: a proposta de aula invertida.

Disponível

em

http://www.pucsp.br/sites/default/files/img/aci/27-8_agurdar_proec_textopara280814.pdf, acesso em 26 de novembro de 2017.

VYGOSTKY, Lev .Pensamento e Linguagem. São Paulo: Martins Fontes.1987

VYGOSTKY, et al.Linguagem, desenvolvimento e aprendizagem.São Paulo: Ícone/EDUSP. 1988. 